\title{
Monitoring Interior and Exterior Wall Inspections within a Virtual Environment
}

\author{
A. Z. Sampaio, D. P. Rosário, and A. R. Gomes \\ Department of Civil Engineering and Architecture, ICIST, IST, Technical University of Lisbon, \\ Avenida Rovisco Pais, 1049-001 Lisbon, Portugal \\ Correspondence should be addressed to A. Z. Sampaio, zita@civil.ist.utl.pt
}

Received 17 January 2012; Accepted 17 October 2012

Academic Editor: Ram M. Pendyala

Copyright ( 92012 A. Z. Sampaio et al. This is an open access article distributed under the Creative Commons Attribution License, which permits unrestricted use, distribution, and reproduction in any medium, provided the original work is properly cited.

This paper describes two prototype applications based on the Virtual Reality (VR) technology for use in maintenance planning of buildings. In a building, the paint coating applied to interior walls and the different types of materials applied to façades convey their aesthetic character and also perform an important function of protection. This a construction component which is exposed to agents of deterioration related to its use, needing the regular evaluation of its state of repair. The applications support the performance of such periodic inspections and the monitoring of interior and exterior wall maintenance, using the VR technology. Used during an inspection visit, the applications allow users to consult a database of irregularities, normally associated with the coating, classified by the most probable causes and by the recommended repair methodologies. In addition, a chromatic scale related to the degree of deterioration of the coating, defined as a function of the time between the dates of the application of the paint and the scheduled repainting, can be attributed to each element of coating monitored. This use of the VR technology allows inspections and the evaluation of the degree of wear and tear of materials to be carried out in a highly direct and intuitive manner.

\section{Introduction}

The main aim of a research project [1], now in progress at the Department of Civil Engineering of the Technical University of Lisbon, is to develop virtual models as tools to support decision-making in the planning of construction management and maintenance, PTDC/ECM/67748/2006, "Virtual Reality technology applied as a support tool to the planning of construction maintenance." A first prototype for the lighting system had already been completed [2]. A second prototype concerning construction planning is now complete [3] and the VR model concerning maintenance of the closure of interior [4] and exterior [5] walls is also finished. This paper describes these two latter models created as part of the overall research project.

These interactive models integrate the Virtual Reality (VR) technology and applications implemented in the Visual Basic (VB) language. The models allow interaction with the $3 \mathrm{D}$ geometric model of a building, visualizing components for each construction. They are linked to databases of the corresponding technical information concerning the maintenance of the materials used as interior and exterior closures. The principal objective of the interactive VR prototypes is to support decision-making in the area of maintenance planning.

Currently, the management of information related to the maintenance of buildings is based on the planning of action to be taken and on the log of completed work. The capacity to visualize the process can be added through the use of threedimensional (3D) models which facilitate the interpretation and understanding of target elements of maintenance and of $4 \mathrm{D}$ models through which the evolution of deterioration can be visually demonstrated and understood. Furthermore, the possibility of interaction with the geometric models can be provided through the use of the Virtual Reality (VR) technology.

Information technology, namely, 4D modeling $(3 \mathrm{D}+$ time) and VR techniques is currently in use both in the construction activity and in education [6]. At the Department of Civil Engineering, some didactic models have already 
been generated. The research project presented in this paper follows on from that previous educational work: two 3D geometric models which support activity in the rehabilitation of buildings [7] and three VR models developed to support classes in civil engineering (wall, bridge, and roof construction) in technical drawing, construction, and bridge disciplines [8]. The didactic VR models are in common use in both face-to-face classes and on an e-learning platform.

The Virtual Reality technology can support the management of data that is normally generated and transformed or replaced throughout the lifecycle of a building. This technology constitutes an important support in the management of buildings allowing interaction and data visualization. At present, the management of building planning can be presented in $3 \mathrm{D}$ form and various materials can be assigned to the fixtures and furnishing enabling the user to be placed in the virtual building and view it from the inside as well as the outside. This study contemplates the incorporation of the 4th dimension, that is, time, into the concept of visualization. The focus of the work is on travelling through time, or the ability to view a product or its components at different points in time throughout their life. In maintenance, the time variable is related to the progressive deterioration of the materials throughout the building's lifecycle. It is implicit that the incorporation of the time dimension into $3 \mathrm{D}$ visualization will enable the designer/user to make more objective decisions about the choice of the constituent components of the building.

The paper describes both maintenance models, highlighting the constitution of the database supporting the models and the organization of a user-friendly interface designed to be used by an inspection worker. During the construction of these models, the basic knowledge of the topics involved, such as aspects related to the materials, the techniques of rehabilitation, and conservation and the planning of maintenance, is outlined and discussed. In addition, methods of interconnecting this knowledge with the virtual model are explored. These prototypes were trailed in an actual project. These aspects of the construction activity are in constant evolution, so require the study of preventive maintenance, through, for example, the planning of periodic local inspections and corrective maintenance with repair activity analysis. For this reason, the model facilitates the visual and interactive access to results, supporting the drawing-up of inspection reports.

\section{Interior Wall Maintenance Model}

The coating applied to building walls, naturally, performs an important aesthetic function; it is, however, essentially a protective element for the substrate on which it is applied as far as the action of environmental agents of wear and tear is concerned. The coating is fundamental to a proper overall performance of a building throughout its working life.

Materials frequently used in the coating of ordinary buildings are, paint, varnish, stone, and ceramics [9]. In Portugal, where interior walls are concerned, the most commonly used coating is paint. It is a multipurpose material, used under a variety of decorative effects, based on a widely ranging palette of colors, patterns, and textures, and is easily applied on any type of surface. In addition, paint, compared to other materials, is less costly, not only as far as the product itself is concerned, but also in its application, since relatively nonspecialized labor is required. Nevertheless, as deterioration is a given, maintenance is needed.

Factors such as the constant exposure of the coating to the weather, pollutants, and the normal actions of housing use, linked to its natural aging and, in some cases, to the unsuitable application of systems of painting, give rise to its deterioration and to the appearance of irregularities, which can negatively affect its performance as both an aesthetic and a protective element. According to Lopes [10], in normal conditions of exposure and when correctly applied, a paint coating can remain unaltered for about five years. Establishing suitable maintenance strategies for this type of coating is based on the knowledge of the most frequent irregularities, the analysis of the respective causes, and the study of the most suitable repair methodologies.

The completed virtual model identifies the elements of the building which make up the interior wall coating so that monitoring can take place. The application is supported by a database, created for the purpose, of irregularities, their probable causes, and suitable repair processes, which facilitates the inspection process. The information is recorded and associated to each monitored element, allowing subsequently the inspection and repair activity log to be consulted, thus providing a tool for the definition of a rehabilitation strategy. In addition, the model assigns a color to each of the coating elements, the colors defined by the time variable, so that the evolution of the deterioration of the coating material is clearly shown through the alteration in color. The prototype is, then, a $4 \mathrm{D}$ model.

The model integrates a virtual environment with an application developed in the Visual Basic programming language. This allows interaction with the 3D model of buildings in such a way that it becomes possible to follow the process of monitoring the coating elements, specifically, painted interior walls, in terms of maintenance, throughout the lifecycle of the building.

2.1. Maintenance. The General Regulation for Urban Buildings (RGEU) [11] stipulates the frequency of maintenance work, stating that existing buildings must be repaired and undergo maintenance at least once every eight years with the aim of eliminating defects arising from normal wear and tear and to maintain them in good usable condition in all aspects of housing use referred to in that document.

The time-limit indicated is applicable to all elements of the buildings generally. It is clear, however, that the regulatory period is too long for some specific components and that, frequently enough, the time-limits for action are not respected. There are, too, inefficient rent policies, leading to long periods without rehabilitation and that the prevailing culture is one of reaction on the part of the various parties involved in the maintenance process. To these aspects should also be added the defects sometimes registered during the construction of property developments, exacerbating the poor state of repair of the buildings. This gives rise to 
numerous irregularities which, in turn, frequently lead to inadequate safety conditions.

According to Cóias [12], the purpose of maintenance is to prolong the useful life of the building and to encourage adherence to the demands of safety and functionality, keeping in mind the specific set of conditions of each case and its budgetary considerations Satisfactory management of this activity is carried out by putting into practice a maintenance plan which must take into consideration technical, economic, and functional aspects arising with each case.

Collen [13] points out that investment in the maintenance and rehabilitation sector in Portugal is still weak compared to that in the same sector in the construction industry in the other countries of the European Community. She makes it clear, however, on a more positive note, that some measures have already begun to be implemented here: some urban regeneration programs have been created, legislation, which focuses on the sustainability of buildings, has been laid down, and the revision of constructive solutions has been carried out, all with the objective of guaranteeing that the maintenance of built heritage be an integral part of the construction sector.

The maintenance of buildings, then, is an activity of considerable importance within the construction industry; its contributory aspects of conservation and rehabilitation work need to be supported by correct methodologies of action, underpinned by scientific criteria and by suitable processes for the diagnosis of irregularities and the evaluation of their causes. This paper aims to make a positive contribution to this field using the new computer technology tools of visualization and interaction.

2.2. Pathologies in Paint Coatings. The technical document Paints, Varnishes and Painted Coatings for Civil Construction published by the National Laboratory for Civil Engineering (LNEC) [9] defines paint as a mixture essentially made up of pigments, binder, vehicle, and additives. It has a pigmented, pasty composition and when applied in a fine layer to a surface, presents, after the dispersion of volatile products, the appearance of a solid, colored, and opaque film [14].

The durability of the painted coating depends on the environment in which it is used and on the surface it is applied to as well as the rate of deterioration of the binder in the paint. The influence of the environment is the result of the action, in conjunction or alone, of a variety of factors such as the degree of humidity, the levels of ultraviolet radiation, oxygen, ozone, and alkalis, and variations in temperature and of other physical or chemical agents whose effect depends considerably on the time taken to apply it [15]. When their influence is not counteracted or minimized, imperfections can arise in the coating film, such as the appearance of defects in the layer or paint with the loss of functionality where the desired aim of the application is concerned.

These irregularities manifest themselves in various ways and in different degrees of severity. Based on the study made of the causes of the defects, specific methodologies for their resolution were established. Figure 1 shows common defects in painted interior walls.

The information gained from the pathological analysis of this type of coating was used to draw up a database supporting the interactive application. These data support the creation of inspection files related to the elements which are monitored in each case studied.

In order to form a user-friendly database of relatable data, groups of pathologies, shown below in Table 1, were considered. This classification provides the required automatism of access to the database and supports the presentation of synopses of the causes and repair methodology inherent in each pathology.

During the process of an on-site inspection, the user of the application can refer to the database in order to classify the abnormality being observed, consulting the list of defects, which includes, in addition to their identification, the most relevant characteristics and some of the causes that could be at the root of their development. Table 2 lists two of the irregularities from the classification: Alteration in color.

The database was created with adequate relations between data, concerning each group of anomalies, in order to present the sequence of anomaly, provable cause, and adequate repair work, to the engineer when they use the virtual model in an inspection situation. The specialist must choose in each case the most appropriate sequence.

2.3. Interactive Model. The completed application supports on-site inspections and on-going analysis of the evolution of the degree of deterioration of the coating. The following computational systems were used in its development: AutoCAD, in the creation of the 3D model of the building; EON Studio [17], for the programming of the interactivity capacities integrated with the geometric model; Visual Basic (VB) 6, in the creation of all the windows of the application and in the establishment of links between components; Microsoft Access, to define a database allowing the association of the virtual model with the relevant information of maintenance activity of interior walls. All the systems were made available by the ISTAR/DECivil [18] of the IST of the Technical University of Lisbon.

First it was necessary to create a 3D geometric model of the building in study. Then the 3D model was transferred to the VR software EON Studio. In this system the geometric elements that represent the interior coating were capable of VR typical characteristics. Thus elements can be monitored through VB routine programming. The model acquires the ability to perform data binding, allowing the data and initial results visualization. In order to connect the virtual model and the database a VB interface was defined. It is through the $\mathrm{VB}$ programming process that the links are created between the 4D/VR file, the database, and all the calculation routines required for the results presentation related to the maintenance activity.

This application is divided into four distinct interfaces connected between them (Figure 2): visualization window, building characterization, inspection, and maintenance interface. The access to the building's windows characterization, inspection, and maintenance is done through the 

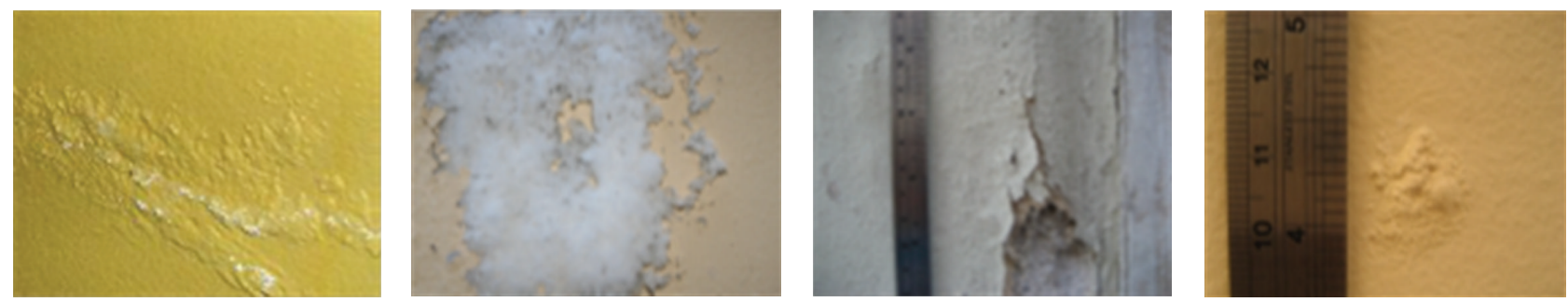

FIGURE 1: Swelling, efflorescence, cracking, and blistering [16].

TABLE 1: Classification of irregularities.

\begin{tabular}{|c|c|c|}
\hline Classification & Irregularity & Repair methodology \\
\hline Alteration in color & $\begin{array}{l}\text { Yellowing } \\
\text { Bronzing } \\
\text { Fading } \\
\text { Spotting } \\
\text { Loss of gloss } \\
\text { Loss of hiding power }\end{array}$ & $\begin{array}{l}\text { Cleaning the surface and repainting with a finish both compatible with } \\
\text { the existing coat and resistant to the prevailing conditions of exposure in } \\
\text { its environment }\end{array}$ \\
\hline Deposits & $\begin{array}{l}\text { Dirt pickup and retention } \\
\text { Viscosity }\end{array}$ & Cleaning the surface \\
\hline Changes in texture & $\begin{array}{l}\text { Efflorescence } \\
\text { Sweating } \\
\text { Cracking } \\
\text { Chalking } \\
\text { Saponification } \\
\end{array}$ & $\begin{array}{l}\text { (i) Removal by brushing, scraping, or washing } \\
\text { (ii) Repainting the surface } \\
\text { (iii) When necessary apply sealer before repainting }\end{array}$ \\
\hline Reduction in adhesion & $\begin{array}{l}\text { Peeling } \\
\text { Flaking } \\
\text { Swelling }\end{array}$ & $\begin{array}{l}\text { (i) Proceed by totally or partially removing the coat of paint } \\
\text { (ii) Check the condition of the base and proceed with its repair where } \\
\text { necessary } \\
\text { (iii) Prepare the base of the paint work }\end{array}$ \\
\hline
\end{tabular}

existing commands in the main window. Another command in the main window allows you to edit the current date. After the date is upset the user should open the virtual model of the study case through the "Open a Virtual Model" command. This command opens a window where the user may choose the VR file (.eoz) to analyze. When opened the virtual model,c the user can begin to use it as it is an EON environment. The main interface gives access to the virtual model of the building and to the inspection and maintenance modules (highlighted in Figure 2).

The first step is to make a detailed description of the building (location, year of construction, type of structure etc., Figure 3) and representative modelced elements of the interior wall coating, so that they can be monitored.

The model is manipulated in the virtual environment by using the mouse buttons (movement through the interior of the model and orientation of the camera, Figure 3 ). The coordinates of the observer's position and the direction of his/her point of view are associated with the element during the process of identification. Thus, later, when an element in the database of the application is selected using the interface, the model is displayed in the visualisation window so that the target coating can be observed.

Walking through the model with the aim of accessing all the elements of the building, the user needs to be able to go up and down stairs or open doors or windows. The virtual model has been programmed, using the EON system, in such a way that these capacities are activated by positioning the cursor over the respective objects; in that way, the user is able to walk through the whole model.

Each wall surface in each of the rooms of the house is a component which has to be monitored and, therefore, to be identified. Using the model, the user must click the mouse on an element and the message New Element is shown (highlighted in Figure 2). Associated to this selected element is the information regarding location within the house (hall, bedroom), wall type (simple internal masonry wall), and coating (paint).

2.4. Making an Inspection. Later, in an on-site inspection visit, the element to be analyzed is selected interactively on the virtual model. The inspection sheet (Figure 5) is accessed by using the Inspection button which is found in the main interface (Figure 2). The data which identify the selected element are transferred to the initial data boxes on the displayed page (Figure 4).

Next, using the database, the irregularity which corresponds to the observed defect, with its probable cause (ageing) and the prescribed repair methodology (removal and repainting), is selected (see the highlighted area, Figure 5). The current size of the pathology should also be indicated since it reveals how serious it is (area of pathology, Figure 5). 
TABLE 2: Irregularities and causes.

\begin{tabular}{|c|c|c|}
\hline Classification & Irregularity & Characteristics and causes \\
\hline \multirow{2}{*}{$\begin{array}{l}\text { Alteration in } \\
\text { colour }\end{array}$} & Yellowing & $\begin{array}{l}\text { (i) A yellow colour caused by ageing of the film of the paint or varnish } \\
\text { (ii) Action of environmental agents (solar radiation, temperature, oxygen, and humidity) } \\
\text { on the binder in the paint provoking changes in its molecular structure }\end{array}$ \\
\hline & Discoloration & $\begin{array}{l}\text { (i) Partial loss of colour of the film of paint coating } \\
\text { (ii) Action of environmental agents (solar radiation, temperature, polluted atmosphere, } \\
\text { and chemically aggressive bases of application) on the binder and/or the pigments of the } \\
\text { painted coating }\end{array}$ \\
\hline
\end{tabular}

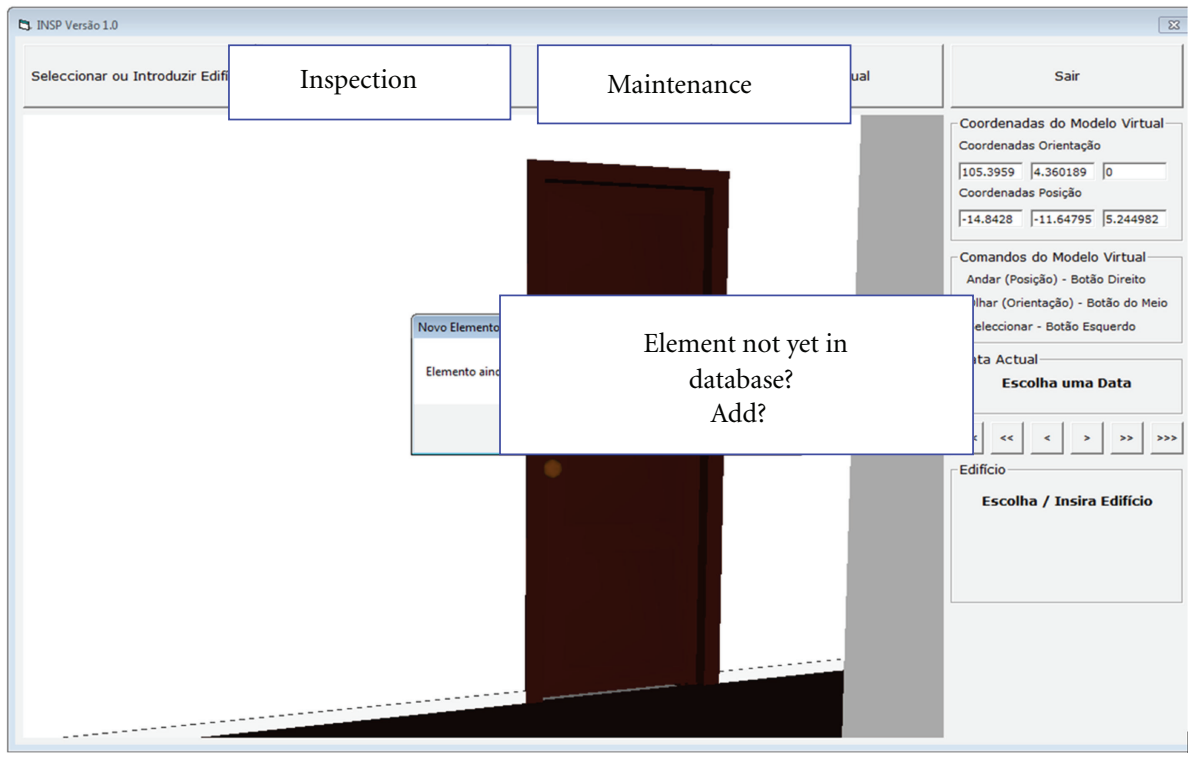

FIGURE 2: The main interface of the virtual application.

In the field Observations, the inspector can add any relevant comment (Figure 4), photographs obtained on site can also be inserted into the inspection window, and the date of the on-site visit and the ID of the inspector should also be added.

Several different irregularities in the same coating can be analysed (field Number of Pathologies, Figure 4) and other elements can be analysed and recorded and defects observed. Later, the files thus created, associated to each of the virtual model elements, can be consulted (Case History button in the Interface in Figure 4). This same window allows all the data referring to the building and to the completed inspection to be shown, in pdf format (Figure 6).

The information concerning each inspection, realized over several interior walls in a building, is recorded and associated to each monitored element. Analyzing all the information collected in an inspection visit to the building, a rehabilitation strategy could be designed and applied. After doing the repairing work, new inspection should be done in order to obtain the real aspect of the painted walls. The photographs obtained before and after doing the repair work can also be compared. All information is recorded and associated to the analysed building elements. A historic report is linked to each monitored building.

Based on the study of this case or of a set of cases, the engineer could establish adequate maintenance strategies for this type of coating, in a general way, or to apply in other building. The engineer depending on the knowledge of the most frequent irregularities, the analysis of the respective causes, the study of the most suitable repair methodologies, and knowledge of costs and the result of repairing works in previous cases should be able to establish more adequate rehabilitation plans. So the model facilitates the visual and interactive access to results of the inspections and reparation work, supporting the drawingup of planning rehabilitation.

2.5. Maintenance Monitoring. How long the working life of any construction component might be is an estimate and depends on a set of modifying factors related to their inherent characteristics of quality, to the environment in which the building is set and to its conditions of use [19]. In a maintenance strategy planning, the probable dates when adverse effects might occur in each of these elements must be foreseen and the factors which contribute to defects must be reduced and their consequences minimized.

The completed model allows the user to monitor the evolution of wear and tear on the paint coating in a house. For this, the technical information relative to the reference for the paint used, its durability, and the date of its most recent application must be added (Figure 7) to each element 


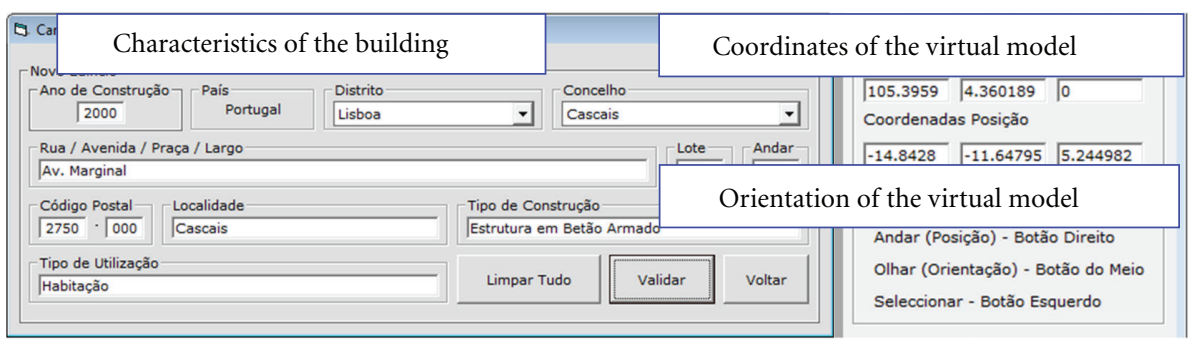

FIGURE 3: Interface for the detailed description of the building and coordinates and manipulation commands in the virtual model.

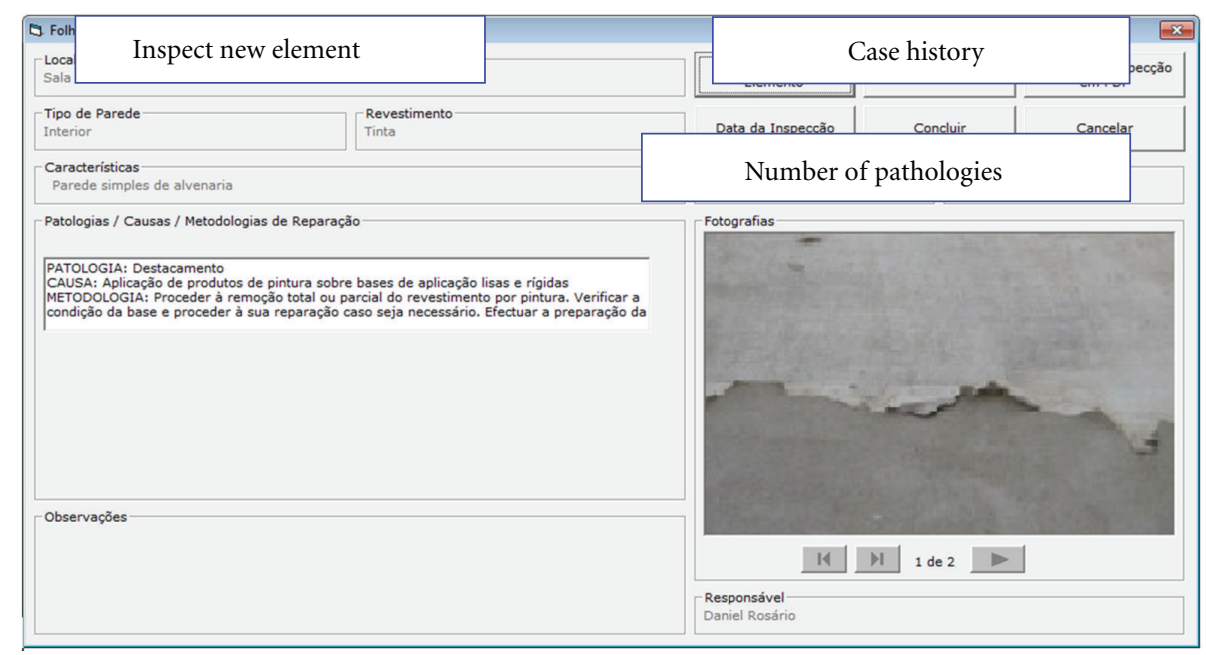

FIgURE 4: Presentation of the information introduced into the inspection sheet.

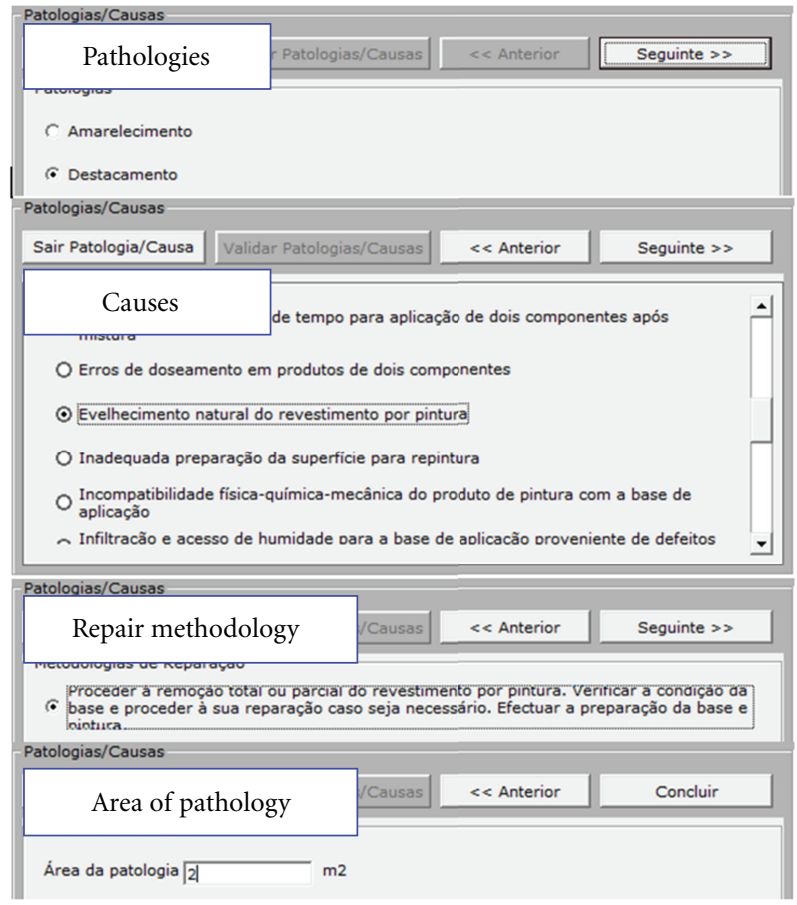

FIGURE 5: Interface for the selection of the irregularity, probable cause, area, and repair methodology. 


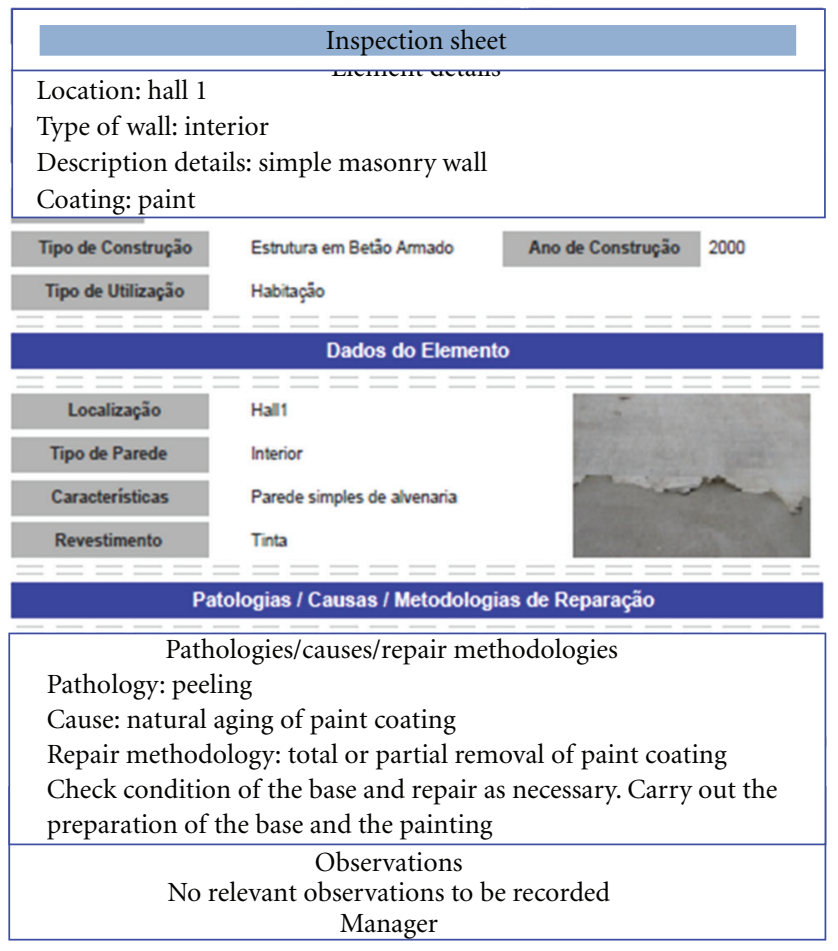

FIgURE 6: Inspection sheet.

through the Maintenance Interface (also accessed from the main interface, Figure 2).

Based on these data, it is possible to link in the date the virtual model is consulted and visualize, in the geometric model, the level of wear and tear as a function of time (see state of repair, Figure 7). The period of time between the date indicated and the date when the paint was applied is compared to the duration advised, in the technical literature, for repainting. The value given for this comparison is associated to the red, green, and blue (RGB) parameters which define the color used for wall in the virtual model (Figure 8).

In this way, the color visualized on the monitored wall varies according to the period of time calculated, pale green being the color referring to the date of painting and red indicating that the date the model was consulted coincides with that advised for repainting (Figure 8).

The data for painting and repainting are saved to a list of coating elements to be monitored in the virtual model. When an element is selected from this list, the corresponding element is represented in the virtual model, through the preview window, in the color that corresponds to the period of the consultation.

2.6. Benefits. Normally the inspection process of buildings is based on filling out paper files during the site survey. The inspector shall observe and analyse the anomalies observed, sort them, and add comments that are timely related to the degree of deterioration, so that, later, establishing a global repair work plan for the building.

With the use of computer system supported on the basis of data relating to the maintenance of the interior wall paint coating, the inspector shall select among the possibilities listed, the anomaly, possible cause and repair methodology that seems more appropriate. Moreover, you can add photos. The definition of the repair plan is based on the analysis of the data entered and selected in the system. The designer, based on the various anomalies observed and on the economic constraints, should establish a proper maintenance plan, encompassing the various anomalies observed. The computer system allows registration, during the inspection, deficiencies, and their seriousness, by supporting the planning of repair work.

When comparing the present model with the façade maintenance model, the principal innovation concerns the incorporation of the capacity of changing the color of the painted wall with the time parameter, when walking through the virtual model. So the evolution of the deterioration of the coating material is visualized through the alteration in color.

\section{Façade Maintenance Model}

Façade coatings play an important role in the durability of buildings, since they constitute the exterior layer that ensures the protection of the wall against the aggressive actions of a physical, chemical, or biological nature. Naturally, they should also give the façade the required decorative effect. Since this building component is exposed to adverse atmospheric conditions, it frequently shows an evident degree of deterioration, requiring maintenance work. In order to arrive at the best solution for eventual maintenance and repair work, a survey of defects and deterioration must be conducted. 


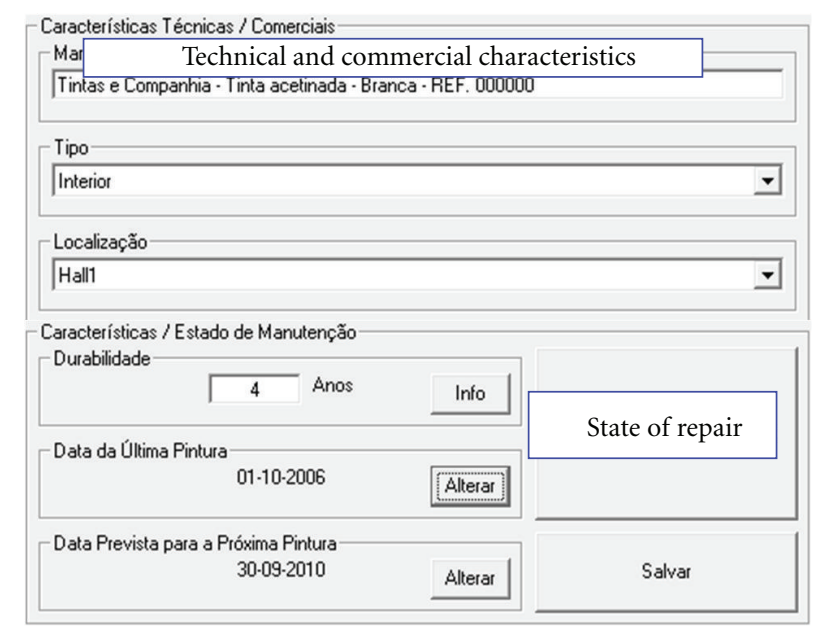

FIgURE 7: Technical characteristics and the durability of the paint-work.
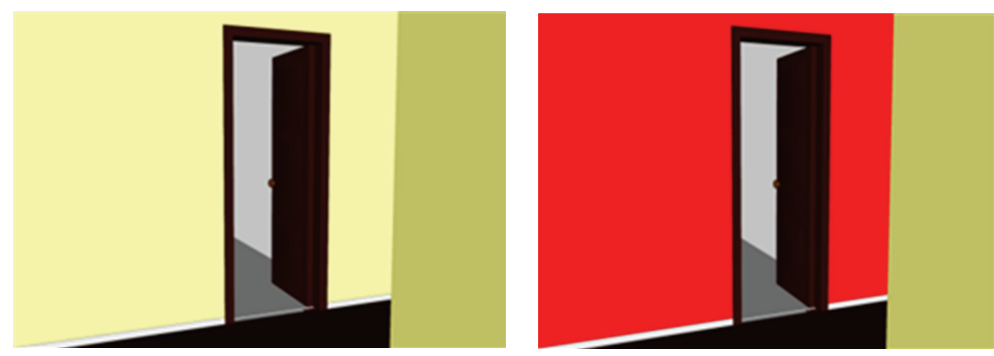

FIGURE 8: Chromatic alteration of the coating according to its state of deterioration.

In order to better understand the operation of façade coating, bibliographic research of materials usually applied to this type of material was carried out and a table of characteristics of these was drawn up. Subsequently, a survey was made of anomalies, probable causes, solutions, and methods of repair for each of the coatings studied. The visualization of the maintenance data of a building and the impact of time on the performance of these exterior closure materials require an understanding of their characteristics [20] (Figure 9):

(i) types of materials: painted surfaces, natural stone panels, and ceramic wall tiles;

(ii) application processes: stones (panel, support devices, adherent products, etc.), ceramic tiles (fixed mechanism, procedures, etc.), painted surfaces (types of paint products, prime and paint scheme surface, exterior emulsion paints, and application processes);

(iii) anomalies: dust and dirt, lasting lotus leaf effect, covering power, insufficient resistance to air permeability or weather-proof isolation, damaged stones or ceramic tiles, alkali and smear effect, efflorescence, fractures and fissures, and so on;

(iv) repair work: surface cleaning, wire truss reinforcing, cleaning and pointing of stonework joints, removing and replacement of ceramic wall tiles, removing damaged paint and paint surface, preparing and refinishing stone panels, and so forth.

Depending on the role that the façade coatings play on the wall as a whole, they can be classified as finishing, sealing, or thermal insulation. The most frequent materials used as coating finishes are painting, tiling, and as sealing coating of the natural stone as follows.

(i) Paint coating contributes to the aesthetic quality of the building and its environment and also protects the surface of the exterior wall against corrosion, deterioration, and penetration of aggressive agents [21].

(ii) The ceramic coating consists essentially of tiling panels, cement and adhesive, and the joints between the slabs. The application of ceramic tiling to building façades has considerable advantages particularly as some degree of waterproofing is afforded by the glazed surface along with a great resistance to acids, alkalis, and vapor [22].

(iii) The use of natural stone in the coating of façade surfaces is a good solution both technically and aesthetically. The principal characteristics of the stones are reduced water absorption, sufficient mechanical resistance to bending and impact, abrasion, and shearing parallel to the face of the slabs. 

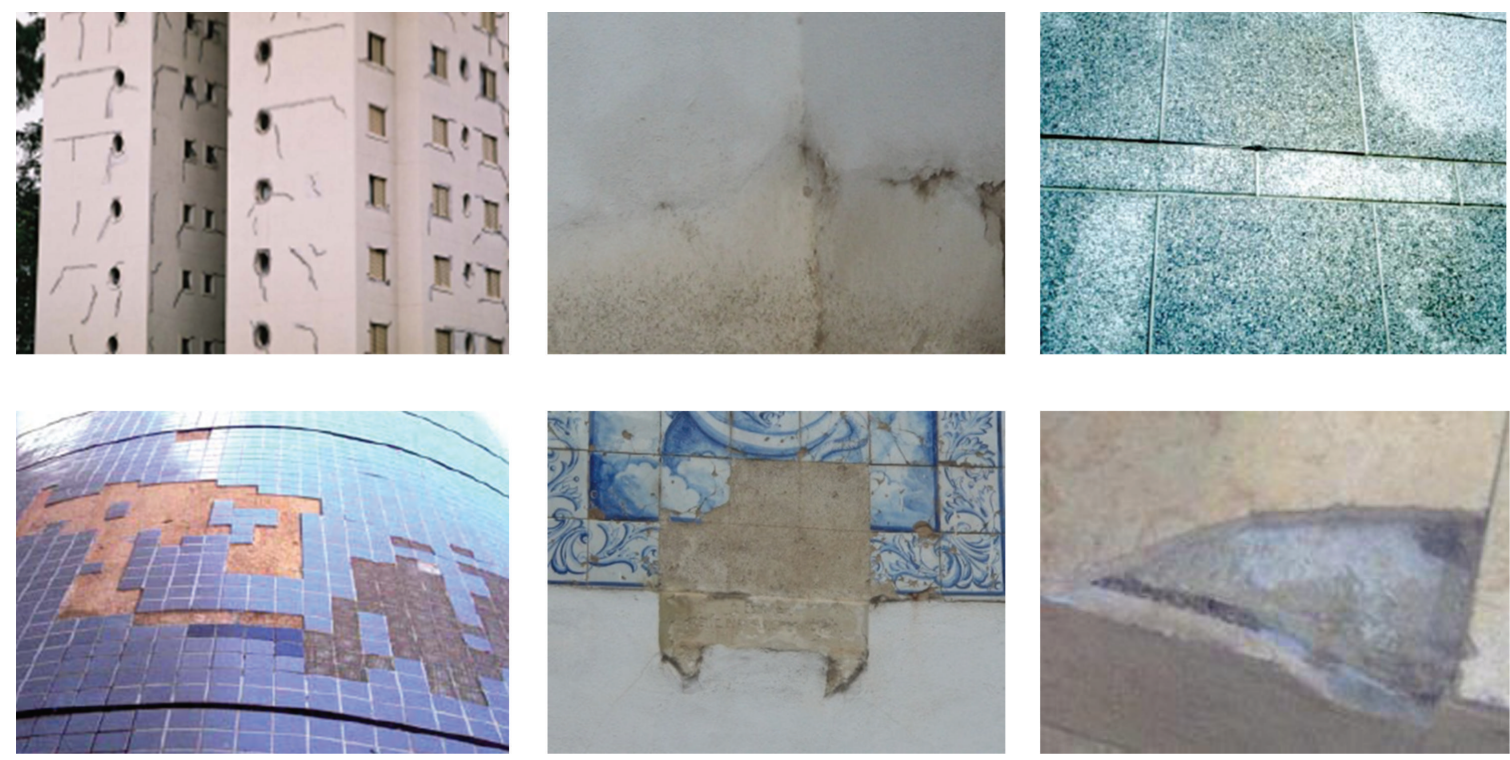

Figure 9: Different types of materials applied as façade coatings and some irregularities.

\begin{abstract}
3.1. Database. The most frequent anomalies that occur in the coated façades were analysed in order to create a database linked to the virtual model that could support the planning of inspections and maintenance strategies in buildings. This database contains the identification of anomalies that can be found in each type of material used in façades and the corresponding probable cause. For each type of anomaly, the most adequate repair solutions were also selected and included in the database. The following example, concerning deficiencies in tiles, illustrates the methodology implemented in this virtual application (Table 3).
\end{abstract}

3.2. Interface. The implementation of the prototype system makes use of a graphical software programming, Microsoft Visual Basic 6.0, a software to establish a suitable database, Microsoft Office Access, a graphical drawing system, Auto$C A D$ Autodesk, and a VR-technology-based software, EON Studio.

Many potential users are not computer experts. Human perceptual and cognitive capabilities, therefore, were taken into account when designing this visualization tool with the result that the model is easy to use and does not require sophisticated computer skills. It uses an interactive 3D visualization system based on the selection of elements directly within the virtual 3D world. Furthermore, associated with each component, there are integrated databases, allowing the consultation of the required data at any point of time.

The interface is composed of a display window allowing users to interact with the virtual model and a set of buttons for inputting data and displaying results (Figure 10).

For each new building to be monitored, the characteristics of the environment (exposure to rain and sea) and the identification of each element of the façades must be defined. The data associated to each element are the building orientation, the type of exterior wall (double or single), and the area and type of coating.
Once each monitored element has been characterized, various inspection reports can be defined and recorded and thereafter consulted when needed. An inspection sheet is accessed from the main interface (Figure 11).

The inspection sheet includes the type of covering (natural stone, Figure 12), the anomalies (cracking/fracturing), and a list of possible causes to be selected and associated to the element. Several photos can be added.

The repair methodology associated to the selected type of anomaly is also presented. These data are then linked to the element. A report history of inspections is permanently associated to the building so that during any later interaction with the model, the inspection report that was defined using the prototype can be accessed.

To sum up, by using the drop-down menus allowed by the interface, the user can associate the characteristics of the observed anomaly to a façade element: the type of anomaly, the specification, details and the probable cause of the anomaly, an adequate repair solution, and pictures taken in the building. After completing all fields relating to an anomaly, the user can present the report as a $p d f$ file.

3.3. Case Study. First, the 3D geometric model of a building was created (Figure 13). In this case, the building consists of a ground floor, a 1st floor, and an attic with dwelling space. The coating elements of the walls were then modeled as independent geometric objects. In this way, each element can then support characterization data of the applied material and different kinds of information related to maintenance.

All coatings studied were considered in this case study. Thus the main façade was assumed to be tiled and the remaining façades painted while hall façades are of natural stone. Figure 14 shows how to identify a façade in the virtual model of the building. Figure 15 shows the inspection report of an anomaly. The developed software is easy to handle and transport for on-site inspections and comprises information 


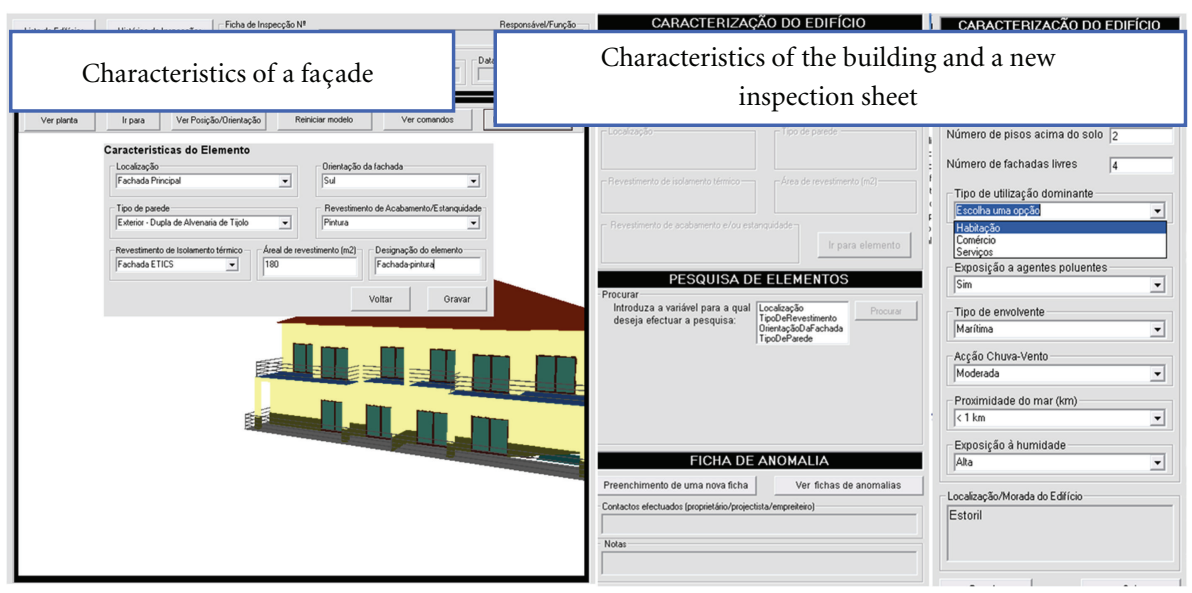

Figure 10: The main interface of the interactive application.

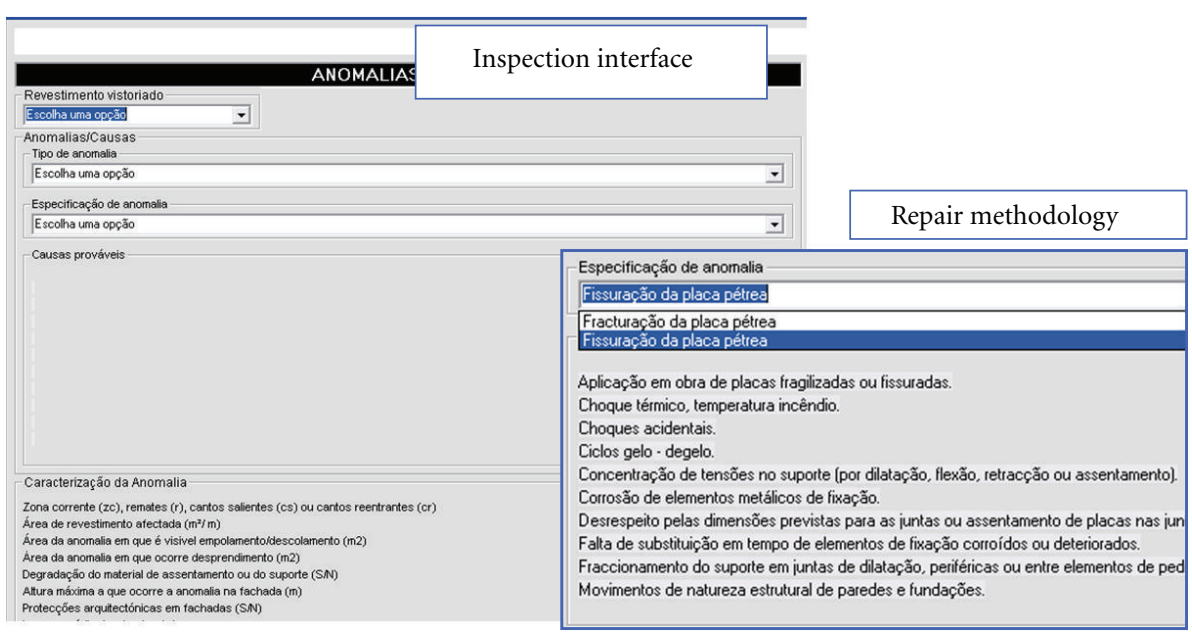

FIGURE 11: Inspection sheet interface.

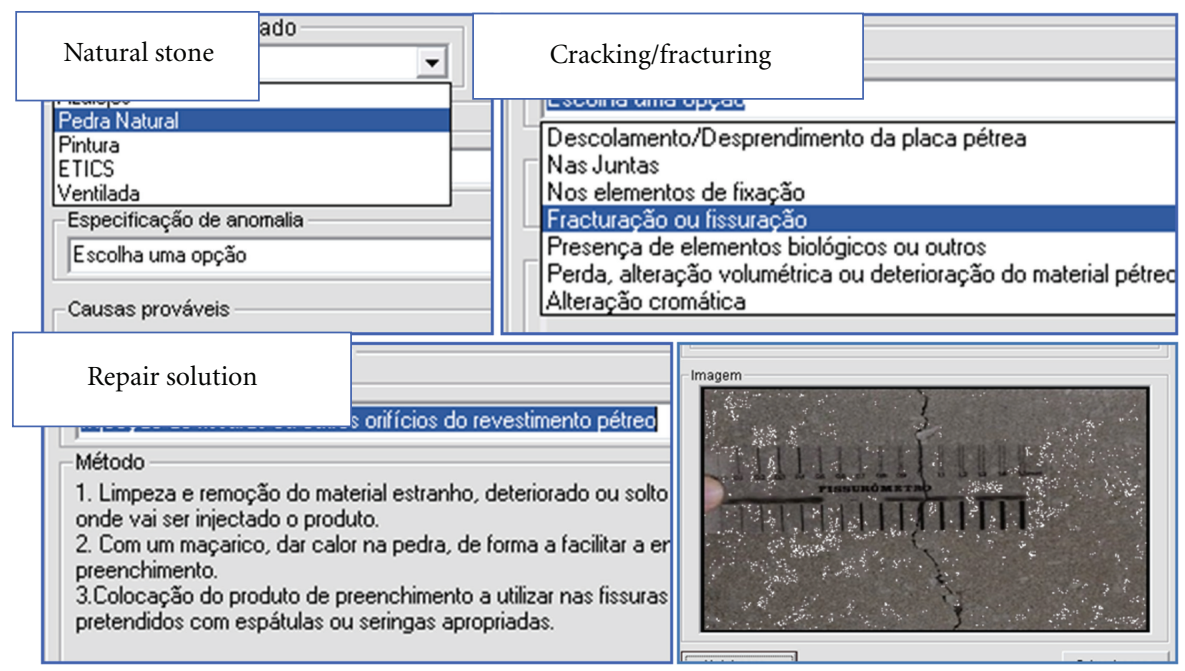

FIGURE 12: Selecting data in the inspection interface. 
TABLE 3: Example of anomalies and the associated repair solution.

\begin{tabular}{ll}
\hline Anomaly & Cracking/fracturing
\end{tabular}
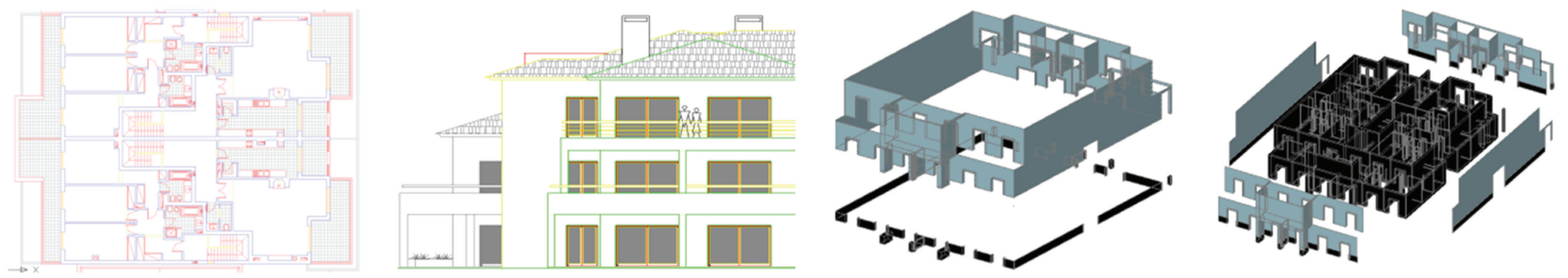

FIGURE 13: Steps in the geometric modelling process.

of the causes, solutions, and methods for repairing anomalies.

\section{Conclusions}

Virtual Reality technology with its capability of interaction and connectivity between elements was employed in the developed prototypes within a research project, offering several benefits both in presenting and developing projects and in supporting decision-making in the maintenance domain.

The VR models support the maintenance of interior and exterior walls enabling the visual and interactive transmission of information related to the physical behavior of the elements. Both models show the characteristics of each element of the building in the model and the information related to inspection, anomalies, and repair works. The information about pathologies, causes, and repair methods, collected from a specialised bibliography, has been organized in such a way as to establish a database to be used as a base for the drawing up of a tool to support building maintenance. The main aim of the application is to facilitate maintenance enabling the rapid and easy identification of irregularities, as well as the possible prediction of their occurrence through the available inspection record. This analysis has been shown as playing an important role in conservation and in the reduction of costs related to the wear and tear of buildings and contributes to the better management of buildings where maintenance is concerned.

As each 3D model is linked to a database in an interactive environment and has a user-friendly interface with easily manipulation of the data, it engenders a collaborative system. With these applications, the user may fully interact with the programs referring to each virtual model at any stage of the maintenance process and can analyze the best solution for repair work. These applications can also support the planning of maintenance strategies and promote the use of IT tools with advanced graphic and interactive capabilities in order to facilitate and expedite the inspection process. The virtual model, moreover, allows users to see, in the virtual environment, the state of repair of the coating.

In addition to the inspection component, a maintenance component was developed which, being visualized in a VR environment as well as being highly intuitive, facilitates the analysis of the state of repair of buildings. By means of a 


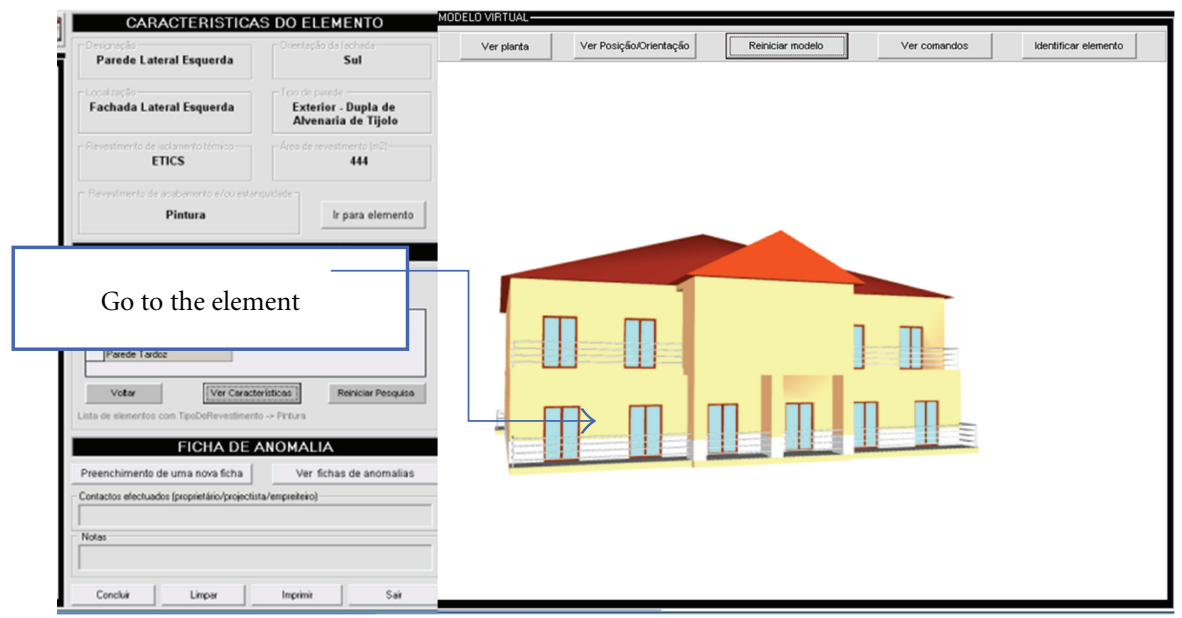

Figure 14: Identification of a façade element.

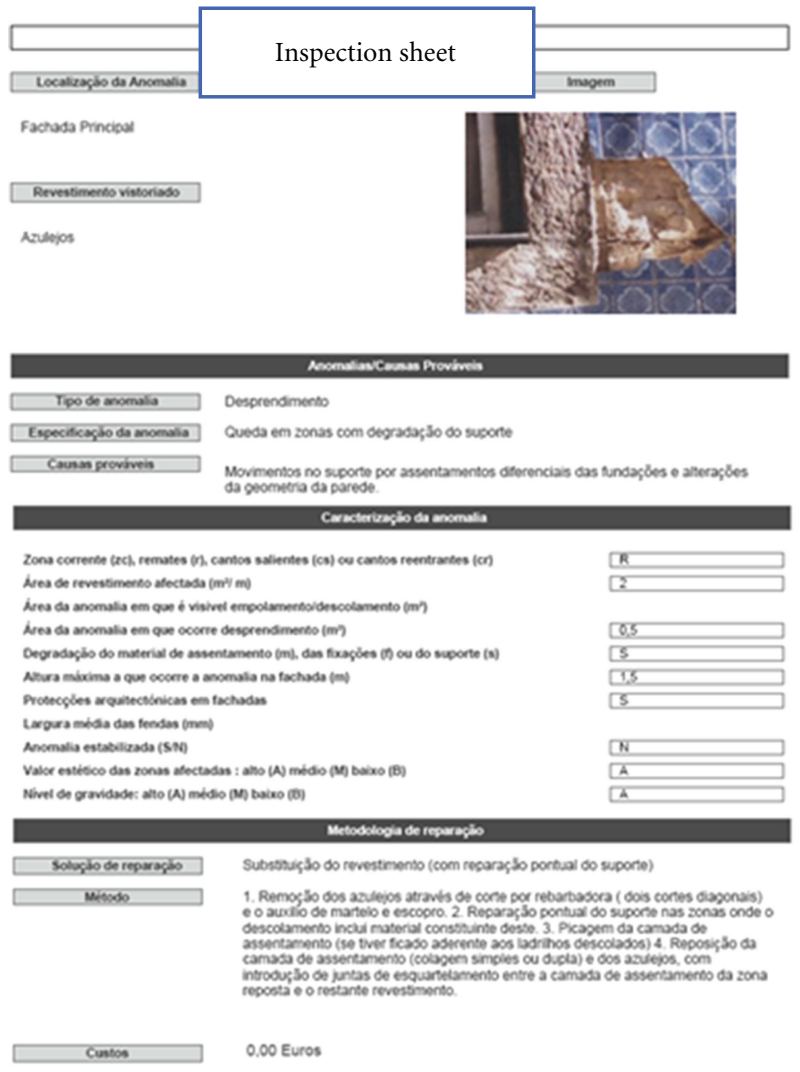

Figure 15: An inspection sheet report.

chromatic scale applied to the monitored elements, displayed in the walk-through of the geometrically modelled building, it is possible to identify the elements which, predictably, will need timely action. With the possibility of altering the time parameter freely, the user can carry out this analysis either for past instants or for future events, being able, in this way, to forecast future operations. This capacity of the model, therefore, contributes to the avoidance of costs associated to irregularities which, with the passage of time, become more serious and therefore more onerous. 


\section{Acknowledgments}

The authors gratefully acknowledge the financial support of the Foundation for Science and Technology, a governmental organization for the Research Project PTDC/ECM/ 67748/2006, "Virtual Reality technology applied as a support tool to the planning of construction maintenance" [1], now in progress.

\section{References}

[1] A. Z. Sampaio and A. M. Gomes, "Virtual reality technology applied as a support tool to the planning of construction maintenance," Research Project PTDC/ECM/67748/2006, FCT, Lisbon, Portugal, 2010.

[2] A. Z. Sampaio, M. M. Ferreira, and D. P. Rosário, "Interactive virtual application on building maintenance: the lighting component," in Proceedings of the 3rd International Conference on Integrity, Reliability and Failure: Challenges and Opportunities, Symposium Visualization and Human-Computer Interaction (IRF 2009), p. 11, Oporto, Portugal, July 2009.

[3] J. P. Santos, Construction planning using 4D virtual models [M.S. thesis in Construction], Technical University of Lisbon, Lisbon, Portugal, 2010.

[4] D. P. Rosário, Virtual reality technology applied on building maintenance: painted interior walls [M.S. thesis in Construction], Technical University of Lisbon, Lisbon, Portugal, 2011.

[5] A. R. Gomes, Virtual reality technology applied to the maintenance of façades [M.S. thesis in Construction], Technical University of Lisbon, Lisbon, Portugal, 2010.

[6] E. H. Mohammed, " $n-D$ Virtual environment in construction education," in Proceedings of the 2nd International Conference on Virtual Learning (ICVL'07), pp. 1-6, 2007.

[7] A. Z. Sampaio, P. G. Henriques, and P. S. Ferreira, "Virtual reality models used in civil engineering," in Proceedings of the 24th IASTED International Conference on Internet and Multimedia Systems and Applications Education (IMSA'06), ACTA Press, Anaheim, Calif, USA, 2006, http://www.informatik.unitrier.de/ ley/db/conf/euroimsa/euroimsa2006.html.

[8] A. Z. Sampaio, M. M. Ferreira, D. P. Rosário, and O. P. Martins, "3D and VR models in civil engineering education: construction, rehabilitation and maintenance," Automation in Construction, vol. 19, no. 7, pp. 819-828, 2010.

[9] M. Eusébio and M. Rodrigues, "Paints, varnishes and painted coatings for civil construction,” CS 14, National Laboratory for Civil Engineering, Lisbon, Portugal, 2009.

[10] C. Lopes, Anomalies in Painted Exterior Walls: Technic of Inspection and Structural Evaluation, Monograph, no. 22, Construlink Press, Lisbon, Portugal, 2004.

[11] RGEU-General Regulations for Urban Buildings, DecreeLaw, no. 38 382, August 1951.

[12] V. Cóias, Inspections and Essays on Rehabilitation of Buildings, IST Press, Lisbon, Portugal, 2nd edition, 2009.

[13] I. Flores-Colen and J. de Brito, "Discussion of proactive maintenance strategies in Façades-coatings of social housing," Journal of Building Appraisal, vol. 5, no. 3, pp. 223-240, 2010 2010.

[14] M. B. Farinha, Construction of Buildings in Practice: Guide Oriented to the Development of Processes and Methodologies of Construction, vol. 2, Verlag Dashofer, Psicosoma Lisboa, 2010, http://www.psicosoma.pt/.

[15] M. I. Marques, "Durability of plastic tint," ITMC 2, National Laboratory for Civil Engineering, Lisbon, Portugal, 1985.
[16] A. Moura, Characteristics and conservation state of painted façades: study case in Coimbra [M.S. thesis in Construction], Technical University of Coimbra, Coimbra, Portugal, 2008.

[17] "EON studio introduction to working in EON studio," EON Reality, Inc., 2011, http://www.eonreality.com/.

[18] ISTAR, Architectural Laboratory of IST, Lisbon, Portugal, 2011, http://www.civil.ist.utl.pt/istar/laboratorios/.

[19] R. M. Webb and T. C. Haupt, "The potential of 4D CAD as a tool for construction management," in Proceedings of the 7th International Conference on Construction Application of Virtual Reality, University Park, Pa, USA, 2003.

[20] A. M. Gomes and A. P. Pinto, Didactic Text of Construction Materials, Technical University of Lisbon, IST, Lisbon, Portugal, 2009.

[21] L. Ferreira, J. Coroado, V. Freitas, and I. Maguregui, "Causes of the fall of tiles applied to exteriors of buildings. Patterned tiling in buildings from 1850-1920," in Proceedings of the 3rd Meeting on Pathology and rehabilitation of Buildlings (PATORREB'09), FEUP, Oporto, Portugal, March 2009.

[22] M. Veiga and S. Malanho, "Natural stone coating: methodology of diagnosis and repair of anomalies (PATORREB'09)," in Proceedings of the 3rd Meeting on Pathology and Rehabilitation of Buildings, FEUP, Oporto, Portugal, March 2009. 

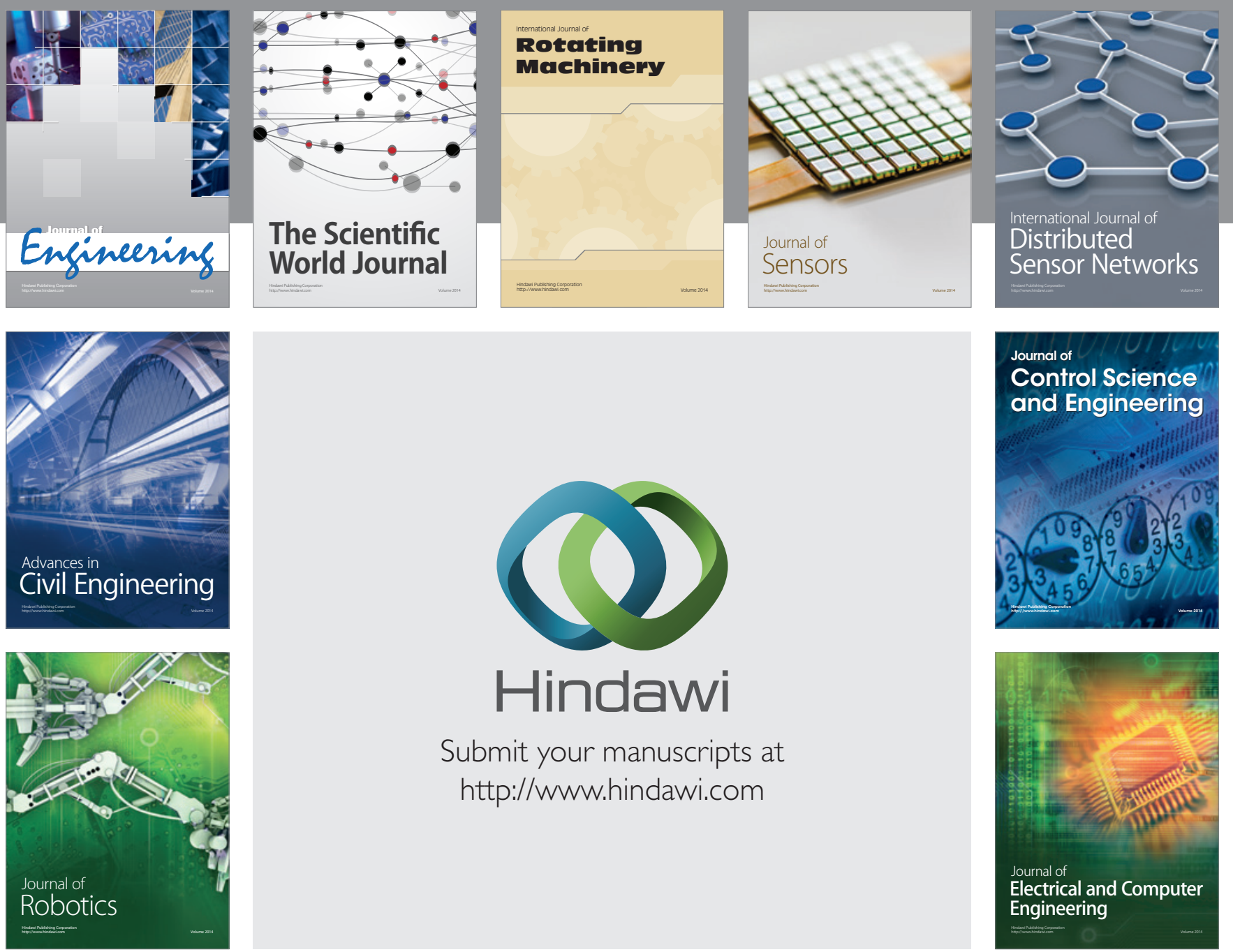

Submit your manuscripts at

http://www.hindawi.com
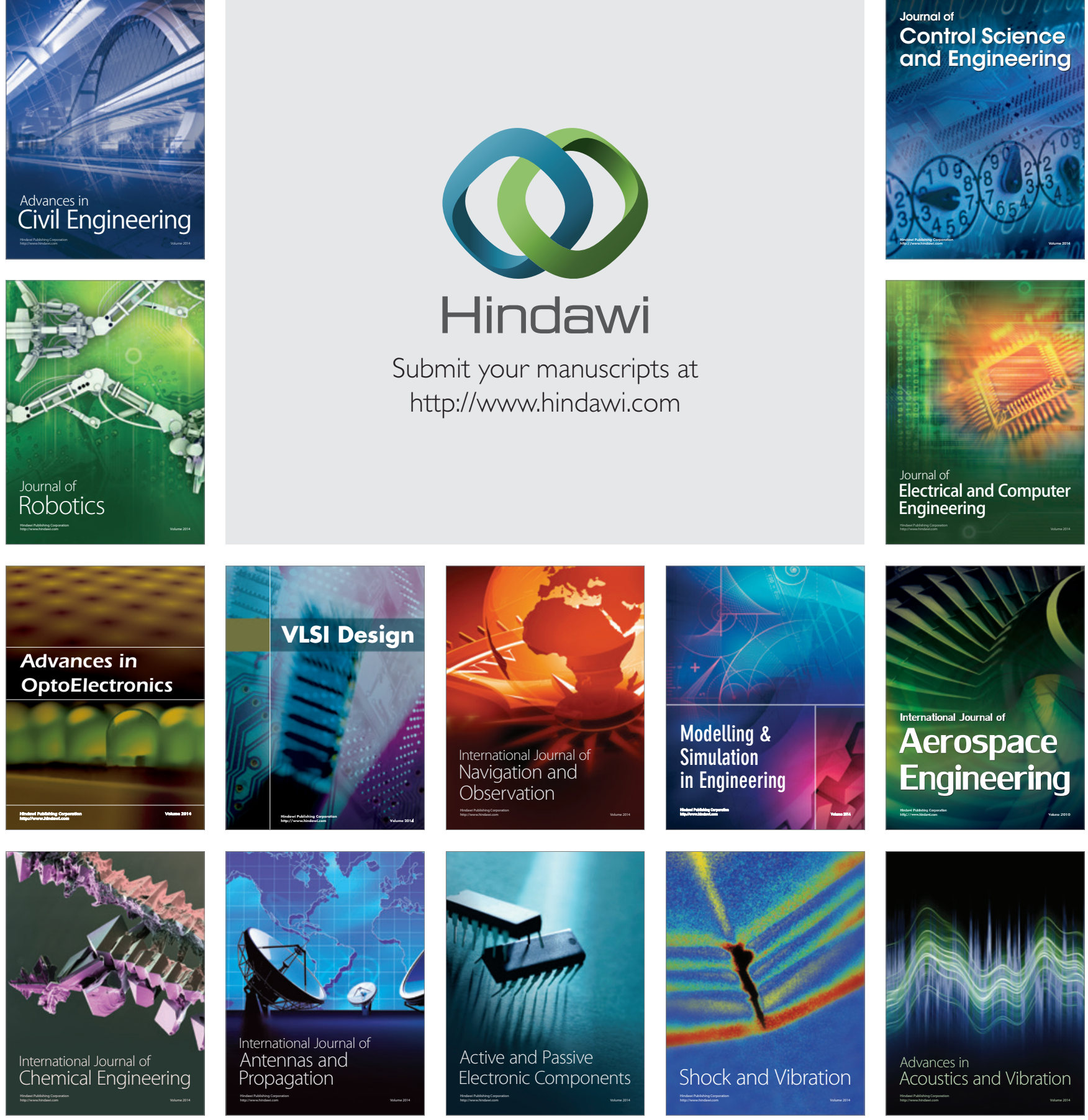